\title{
Simulation of a purification plant for pyrolysis gas based on plastic waste
}

\author{
Ebrahim Qaredaghi $^{1} \quad$ Sara Ronasi $^{2} \quad$ Britt M. E. Moldestad ${ }^{1}$ \\ ${ }^{1}$ Department of Process, Energy and Environmental Technology, University of South-Eastern Norway, Norway, \\ qaredaghi@gmail.com Britt.Moldestadeusn.no \\ ${ }^{2}$ Norner Research, Norway, sara.ronasienorner.no
}

\begin{abstract}
This study focuses on exctracting ethylene and propylene from other componenents in the pyrolysis gas mixture of plastic waste. Selective absorption of ethylene and propylene from the gas mixture by using a silver nitrate solution, was selected as a promising technology. A lab scale set-up was built and experimental tests were performed using a model gas mixture. Aspen HYSYSV10 was used to model and simulate the absorption process. The model was validated against experimental data. The validated model was further used to identify improvements for the separation process and increase the recovery of ethylene and propylene. The results from the simulated improved process show that the amount of ethylene and propylene in the product gas could be significantly increased. In the experimental study, only $25 \%$ of ethylene and propylene in the feed was captured, whereas the simulation of the improved process indicates that the recovery of the monomers could be almost quantitative (99\%). However, the product gas from the separation system contained an undesirable high amount of $\mathrm{CO}$ and $\mathrm{CO}_{2}$. These gases act as pollutants of the polyolefin reaction and further studies are needed to obtain pure olefin gases.
\end{abstract}

Keywords: plastic waste, purification, ethylene, propylene, absorption, pollutants, Aspen Hysys, process simulation

\section{Introduction}

Global production of plastics has since 1940 become one of the fastest growing industries in the world. PlasticsEurope (PlasticsEurope, 2019) and the European Association of Plastics Recycling and Recovery Organizations (EPRO, 2018) reported that the global plastic production in 2017 was 348 million tons, out of which 64.4 million tons were produced in Europe. The largest plastic producers were China and Europe by producing $29.4 \%$ and $18.5 \%$ of the total respectively. (G. Gourmelon, 2015; A. Demirbas, 2004) The European commission has presented a plan to implement a circular economy with a key focus on plastics. The plan is set to ensure that all plastic packaging is reused or recycled by the year 2030 .
(Plastics Europe, 2019). According to EUs circular Economy Package and directive (EU) 2018/850 adopted by the European parliament and by the EU council in 2018. Member States will be required to ensure that, as of 2030, waste suitable for recycling or other recovery, in particular contained in municipal waste, will not be permitted to be disposed of to landfill. The re-processing operation in mechanical recycling is not cost effective since this process has high energy demand for sorting, cleaning, transportation and processing (Panda et al., 2010). Chemical recycling is the state of the art feedstock recycling, also known as tertiary recycling. The aim is to convert waste polymers into valuable chemicals or original monomers. Cracking is one of the main approaches to this method (Panda et al., 2010).

The aim of this study is a) to carry out experimental separation tests to obtain pure ethylene and propylene, and b) to develop a process simulation model that can be used to optimize the purification process. In order to obtain the requested purity grade for polymerization of ethylene and propylene, there are two options. The first option is to focus on ethylene and propylene and try to extract them from the other components in the pyrolysis gas. The second option is to remove all impurities in the pyrolysis gas one by one. The first option was chosen in this study, and absorption is used to extract ethylene and propylene from a gas mixture.

\section{Purification process}

Figure 1 illustrates the general steps of sustainable polymer production from biomass or plastic waste. Plastic waste or biomass is fed to the pyrolysis reactor. The composition of the outlet gas from the reactor is highly dependent on the composition of the plastic waste. In the pyrolysis process, the components of the plastics can be converted into solid (char), liquid (pyrolysis oil) and gas (Dermibas, 2004). The product gas is collected from the top of the pyrolysis reactor, and in order to use the gas in the plastic production process, a purification process is needed. The polymerization reaction is sensitive to impurities, and all impurities should be removed from the gas. Therefore, the purification process has an essential role in the whole process. The products from the polymerization process are polyethylene (PE) and polypropylene (PP). 


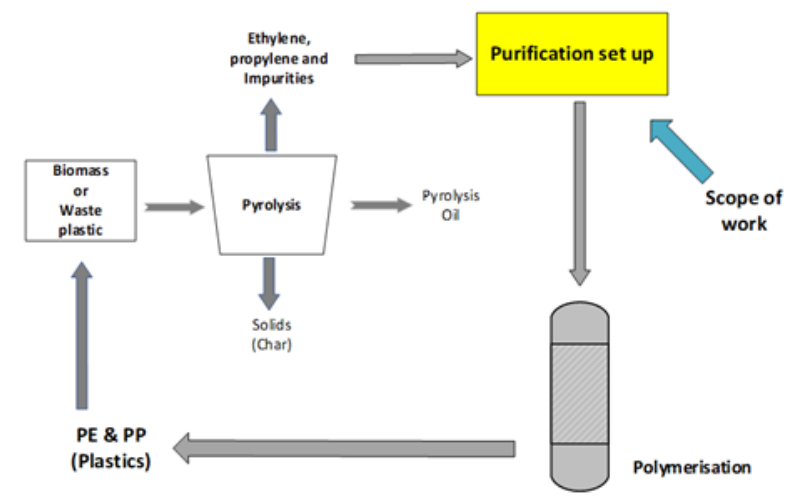

Figure 1. Simplified overview of the plastic recycling process.

Thermal pyrolysis is a well-known method for managing and recycling plastic waste. The composition of the product gases from the pyrolysis reactor can vary due to differences in the composition of the plastic wastes used as feed to the pyrolysis reactor. Hydrogen, oxygen, light olefins (ethylene, propylene, butene), aromatics (benzene, toluene, xylene), polycyclic aromatic hydrocarbons (PAHs), carbon monoxide (CO), carbon dioxide $\left(\mathrm{CO}_{2}\right)$ are the main gaseous component (Donaj et al., 2012; Xue et al., 2016).

Several methods and technologies to be used for purification of the pyrolysis gases are found in literature. An absorption process based on the silver-olefin complexation mechanism was chosen to extract ethylene and propylene from the other gas components (Ananthapadmanabhan and Goddard, 1988; Safarik and Eldridge, 1998; Li, 2013). The advantages of the process is that it can selectively extract the ethylene and propylene from the pyrolysis gas as the silver ions bind ethylene and propylene while they do not interact with $\mathrm{CO}$ and $\mathrm{CO}_{2}$. $\mathrm{CO}$ and $\mathrm{CO}_{2}$ are considered as poisons for the polymerization process, and it is crucial to minimize the content of those components in the purified gas. A disadvantage with the process is that the silver nitrate is expensive, and it is very important that it can be regenerated without significant degradation.

Mortaheb et al developed a mathematical model and studied the absorption of ethylene from an ethyleneethane gas mixture by using a silver nitrate solution in a semi-continuous process. The model includes that absorption is a function of temperature and concentration of the absorbing solution. According to the experimental results, an increase in temperature decreases the amount of absorbed ethylene. Furthermore, the amount of absorbed ethylene is increased in solutions with higher concentrations of silver nitrate. Figure 2 compares the total absorption values from the model with experimental data for two different silver nitrate molarities (Mortaheb et al., 2009).

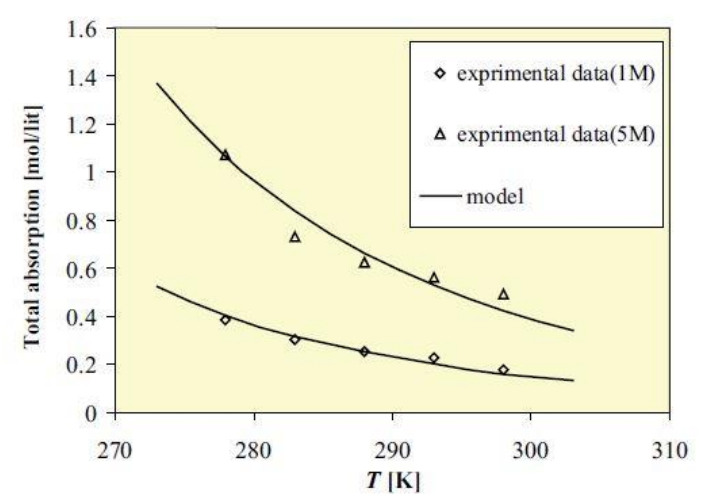

Figure 2. Comparison of total absorption with estimated values by the model (Mortaheb et al, 2009).

A mathematical model proposed by Ghasem et al presents the solubility of ethylene as a function of silver nitrate concentration, feed gas pressure and temperature. Ghasem et al studied the separation of ethylene from an ethylene/ethane gas mixture using a hollow fiber membrane. The model is valid at pressure up to 0.64 $\mathrm{MPa}$, silver nitrate concentrations from 1 to $6 \mathrm{M}$ and temperatures from 278 to $308 \mathrm{~K}$. Figure 3 shows the ethylene solubility in silver nitrate solution as a function of the feed gas pressure and the silver nitrate concentration. The solubility of ethylene increases with increasing pressure and with increasing concentration of the silver nitrate solution (Ghasem et al, 2017).

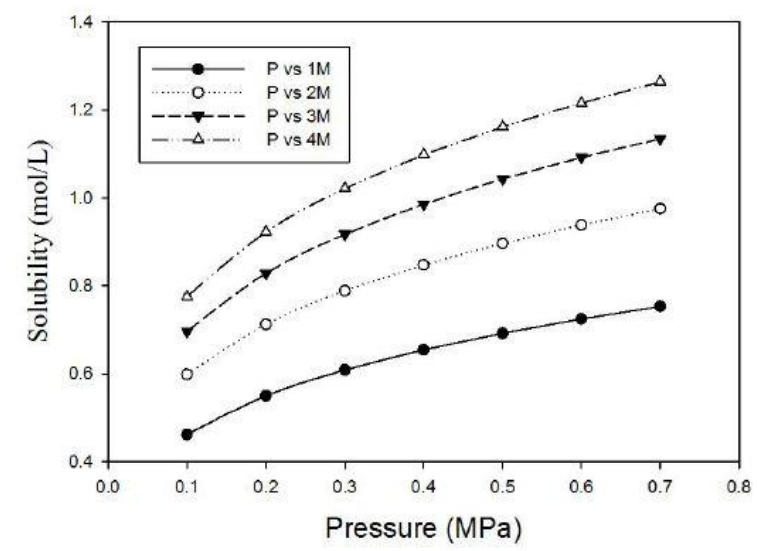

Figure 3. Ethylene solubility in silver nitrate solution as a function of gas pressure and silver nitrate concentration (Ghasem et al, 2017).

\section{Material and methods}

\subsection{Experimental set-up}

The experimental set-up is shown in Figure 4. The test rig consists of a reactor where the aqueous silver nitrate solution is filled. The reactor is connected to a highpressure vessel which is again connected to the main gas mixture capsule. The piping from the top of the reactor is connected to vent, to an aluminum gas collection bag and to a vacuum bomb. Each line has valves to control the flow. A digital temperature indicator and a pressure 
indicator are connected to the reactor to monitor the temperature and pressure inside the reactor. Nitrogen is connected to the feeding line, and is used to purge the system. A gas chromatograph (GC), with helium as the carrier gas, was used for the analysis of the gas samples.

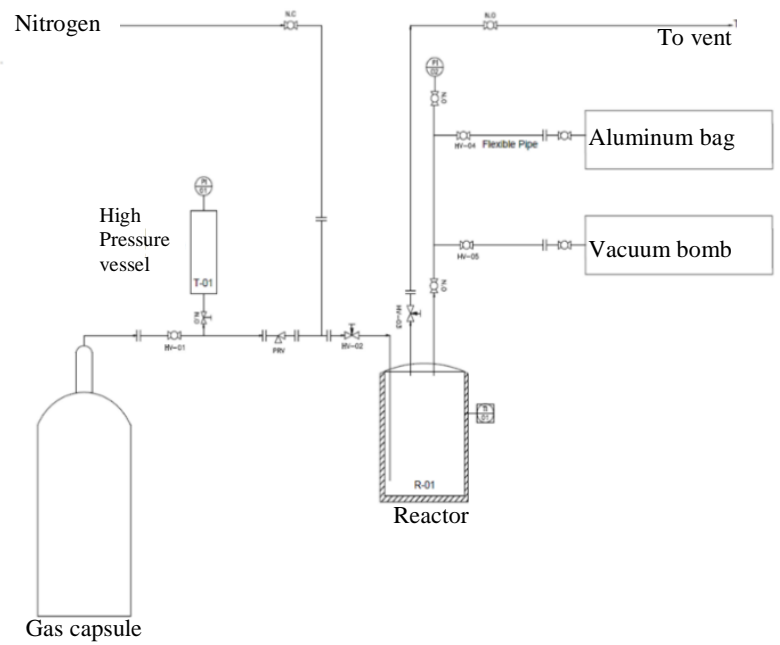

Figure 4. Experimental set-up for extraction of ethylene and propylene.

\subsection{Simulation model}

The process simulation software Aspen HYSYSV10 is used to model and simulate the purification process. There are several thermodynamic models available in the Aspen HYSYSV10 library. In order to obtain accurate simulation results, it is crucial to choose the appropriate thermodynamic model. The three main thermodynamic groups of models are the equation of state (EOS), the activity coefficient models and some special models which are related to specific components. In this study an activity coefficient model was used. Activity coefficient models are applied for highly non-ideal polar systems, and are empirical models. In these models, an equation of state is used for predicting the vapor fugacity coefficients and an activity coefficient model is used for the liquid phase (Aspen HYSYS Software, 2014). Different models were tested, and the Electrolyte Non-Random Two-Liquid (eNRTL) model was chosen for the simulations. The reason for choosing the eNRTL model, is that silver nitrate is a strong electrolyte (Keller et al, 1992). The eNRTL model covers a wide variety of aqueous and mixedsolvent electrolyte systems covering the whole concentration range from fused salts or pure solvents to saturated solutions (Chen and Song, 2004).
Figure 5 shows a set-up for the absorption process developed in Aspen HYSYS. The absorbent silver nitrate (Lean Solution) and the gas mixture (Feed Gas) are fed to the absorption tower (Absorber Tower-100) to extract ethylene and propylene from the gas mixture. The pressure in the absorber is the same as in the feed gas and the absorbent. The absorption is the first step in the ethylene and propylene separation.

The rich silver nitrate solution from the absorber contains the absorbed ethylene and propylene together with some impurities. The solution is fed to a distillation tower (Distillation Tower-102), where most of the impurities goes to the top of the tower and to vent. The absorbent including ethylene and propylene is taken out in the bottom, and fed to the next distillation tower (Distillation Tower-103), which operates at a lower pressure. In this tower ethylene and propylene are separated from the silver nitrate solution. The distillation tower (Distillation Tower-103) is operated under vacuum to capture as much as possible of the ethylene and propylene gases from the solution. The regenerated lean absorbent is taken out in the bottom of the distillation tower, and is recycled to the absorption tower. In order to ensure that the temperature and pressure of the recycled absorbent is the same as in the absorption tower, the Set-functions are defined to adjust the pressure after the pump (Pump-100) and the temperature after the heat exchanger (Heat-Exchanger$100)$. The recycle function (RCY-1) in the regeneration loop, is defined to update the estimated values in the lean absorbent stream.

Since the extraction of ethylene and propylene with silver nitrate follows the $\pi$-complexation mechanism and does not include chemical reactions, distillation columns are used for the separation of the components from the absorber. In order to develop a robust model to simulate the ethylene and propylene absorption, the model has to be validated against the experimental data. A one-stage absorber, as used in the experimental study, is therefore chosen for the development of the model. The validated model can further be improved by including multiple stages, in order to obtain the desired separation. A packed absorber is used in the simulations. The reason for choosing a packed absorber instead of the tray type, is to minimize the inventory of silver nitrate in the absorber (Keller et al, 1992). The pressure in the absorber is $1700 \mathrm{kPa}$. The diameter of the absorber is $1.5 \mathrm{~m}$ and the packing height is $0.61 \mathrm{~m}$. 


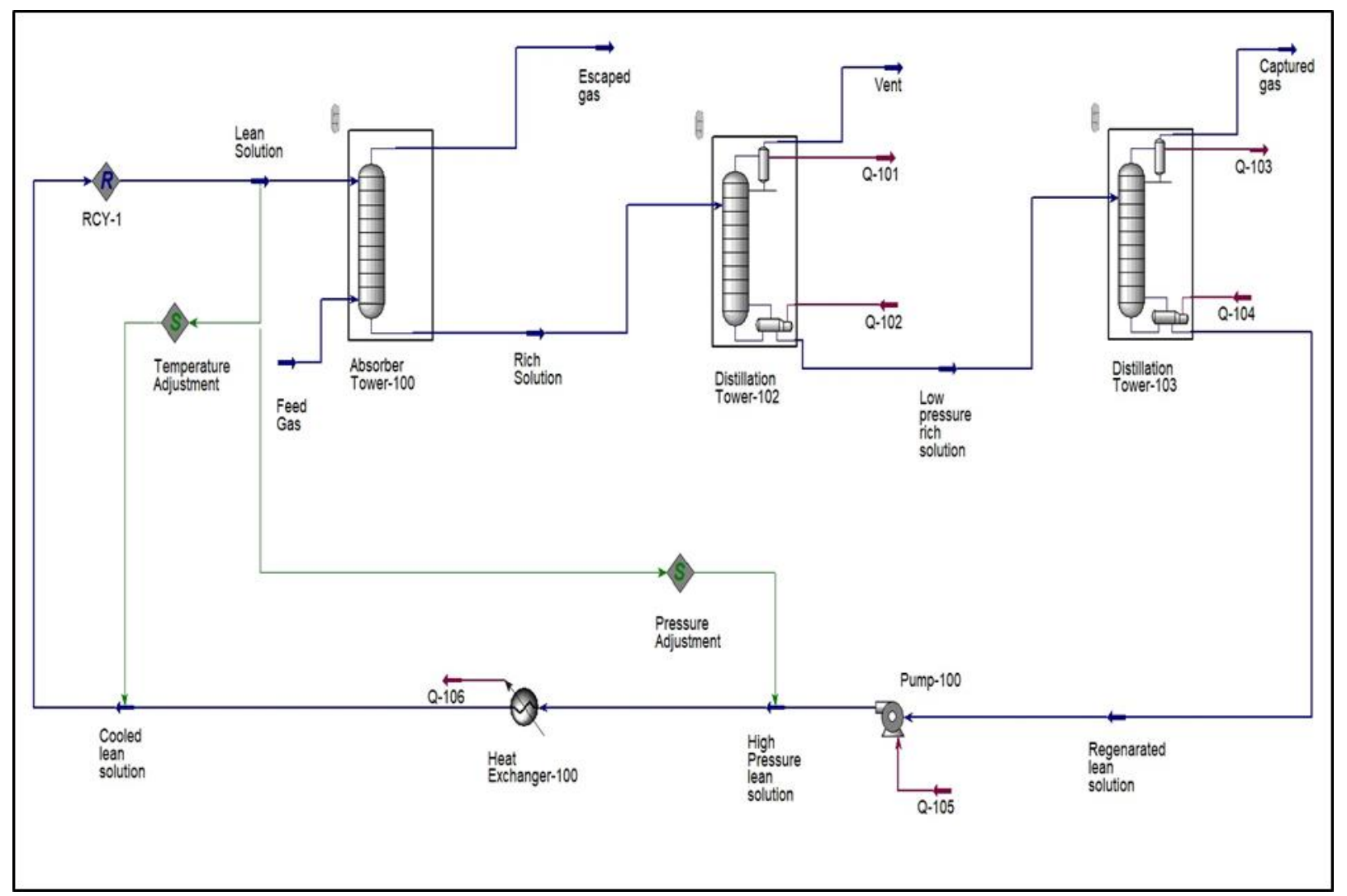

Figure 5. Simulation model for ethylene and propylene separation

\section{Results}

\subsection{Experimental results}

The solubility of ethylene and propylene in a silver nitrate solution is a function of gas pressure and silver nitrate concentration. Experiments were carried out using a $3 \mathrm{M}$ silver nitrate solution at ambient temperature and at initial pressure of $41 \mathrm{bar}$. The composition of the feed gas to the absorber is presented in Table 1 .

Table 1. Feed gas composition.

\begin{tabular}{|c|c|c|}
\hline Component name & Mass fraction & Mole fraction \\
\hline $\mathrm{C}_{2} \mathrm{H}_{4}$ & 0.2 & 0.2185 \\
\hline $\mathrm{C}_{3} \mathrm{H}_{6}$ & 0.2 & 0.1456 \\
\hline $\mathrm{CO}$ & 0.05 & 0.0546 \\
\hline $\mathrm{CO}_{2}$ & 0.05 & 0.0349 \\
\hline $\mathrm{N}_{2}$ & 0.5 & 0.5463 \\
\hline
\end{tabular}

A series of experiments were carried out to study the absorption of ethylene and propylene in silver nitrate. Two of the experiments are presented in this paper. The pressures in the different tanks are presented in Table 2. The same pressures were used as input to the simulation model. One of the big challenges during the experiments, was to obtain exactly the same pressure in all the tests. In theory, the absorption of olefins increases with increasing pressure (Keller et al, 1992). In the experimental setup, it was very difficult to maintain a stable pressure during the absorption at pressures higher than 17 bar (final pressure R1). The pressure was therefore kept at 17 bar, but still some pressure variations between the experiments were observed. Therefore, only two experiments (one with new silver nitrate solution and one with reused solution) are presented here. The results from these two experiments will further be used for validation of the process simulation model. The pressure in the vacuum bomb and the aluminum bag are critical for the results of the tests.

Table 2. Operating pressures for the absorption process

\begin{tabular}{|l|l|l|}
\hline Pressure [bara] & $\begin{array}{l}\text { Exp. 1 } \\
\text { (New } \\
\text { solution) }\end{array}$ & $\begin{array}{l}\text { Exp. 2 } \\
\text { (Reused } \\
\text { solution) }\end{array}$ \\
\hline Initial pressure (R-01) & 41.03 & 41.01 \\
\hline Final pressure (R-01) & 17.01 & 17.01 \\
\hline Vacuum bomb & 5.51 & 5.51 \\
\hline Initial alum. bag & 17.01 & 17.01 \\
\hline Final alum. bag & 1.05 & 1.05 \\
\hline
\end{tabular}

Table 3 presents the results of the experiments (Kannan, 2019), and shows the recovery of the different gas components in the captured gas. Due to the limitations in the analysis set-up, nitrogen was injected into the vacuum bomb to enable feeding of the sample to the gas chromatograph. 
Table 3. Mole \% recovery of each component in the captured gas.

\begin{tabular}{|l|l|l|l|l|l|}
\hline & $\mathrm{CO}_{2}$ & $\mathrm{CO}$ & $\mathrm{N}_{2}$ & $\mathrm{C}_{2} \mathrm{H}_{4}$ & $\mathrm{C}_{3} \mathrm{H}_{6}$ \\
\hline Ex. 1 & 8.4 & 1.82 & 0.01 & 25.5 & 25.5 \\
\hline Ex. 2 & 7.5 & 1.26 & 0.01 & 25.6 & 24.7 \\
\hline
\end{tabular}

Based on the results and the mass balance over the different units in the set-up, the mass flow rate for each stream was calculated (Kannan, 2019). The results from the experiments were used to design a cleaning process for an inlet gas flow rate of $10 \mathrm{~kg} / \mathrm{h}$. Table 4 presents the calculated mass flow rates for the different streams based on the two experiments.

Table 4. Mass flow rates for the process streams.

\begin{tabular}{|l|l|l|}
\hline & $\begin{array}{l}\text { Exp. 1 } \\
{[\mathrm{kg} / \mathrm{h}]}\end{array}$ & $\begin{array}{l}\text { Exp. 2 } \\
{[\mathrm{kg} / \mathrm{h}]}\end{array}$ \\
\hline $\begin{array}{l}\text { Inlet silver nitrate } \\
\text { solution }[\mathrm{kg} / \mathrm{h}]\end{array}$ & 189 & 203 \\
\hline Inlet gas flow $[\mathrm{kg} / \mathrm{h}]$ & 10.0 & 10.0 \\
\hline Escaped gas $[\mathrm{kg} / \mathrm{h}]$ & 7.70 & 7.70 \\
\hline Vent gas $[\mathrm{kg} / \mathrm{h}]$ & 0.85 & 0.91 \\
\hline Captured gas $[\mathrm{kg} / \mathrm{h}]$ & 1.40 & 1.40 \\
\hline
\end{tabular}

As can be seen from Table 4, a large part of the feed gas leaves the absorber as escaped gas, which suggests need for improvement of the experimental set-up.

\subsection{Simulation results}

The process simulation is validated against the experimental results, and the validated model is further improved to get a higher recovery of ethylene and propylene in the captured gas.

\subsubsection{Validation of model}

Table 5 shows the simulated and the experimental flow rates of the captured and escaped gas. The simulated flow rates of the captured gas are higher than the experimental results, whereas the escaped gas flow rates are higher in the experiments than in the simulations. This can be due to more ideal and stable operation conditions in the simulations.

Figure 6 shows a comparison of the simulated and experimental composition of the captured gas. Some deviations between the computational and experimental results are observed. The experimental mole fraction of ethyelene are significantly higher than the simulated mole fraction, whereas the experimental mole fractions for propylene, $\mathrm{CO}_{2}$ and $\mathrm{CO}$ are slightly lower than in the simulations. The reason may be variations in the feed of silver nitrate to the absorber. The deviations can also be explained by the tray efficiency, which had to be adjusted in the software in order to the obtain convergence.

In Table 6, the recovery of the different components in the captured gas is presented. The recovery of ethylene and propylene is significantly higher than in the experiments, which is beneficial for the extraction process. However, the process simulation also gives a significantly higher absorption of the unwanted components $\mathrm{CO}$ and $\mathrm{CO}_{2}$.

Table 5. Mass flow rates for the process streams.

\begin{tabular}{|l|c|c|}
\hline & $\begin{array}{c}\text { Flow rate capured } \\
\text { gas }[\mathrm{kg} / \mathrm{h}]\end{array}$ & $\begin{array}{c}\text { Flow rate escaped } \\
\text { gas }[\mathrm{kg} / \mathrm{h}]\end{array}$ \\
\hline Exp. 1 & 1.4 & 7.7 \\
\hline Exp. 2 & 1.4 & 7.7 \\
\hline Sim. 1 & 1.8 & 5.8 \\
\hline Sim. 2 & 1.7 & 5.8 \\
\hline
\end{tabular}

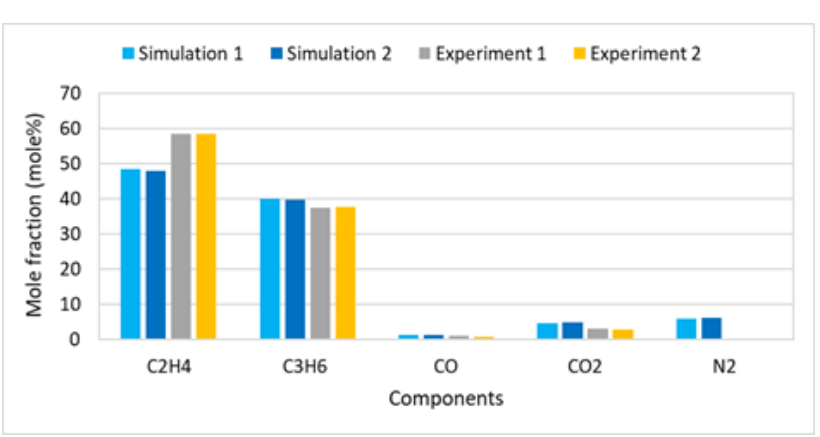

Figure 6. Comparison of simulated and experimental composition of captured gas.

Table 6. Simulated mole \% recovery of each component in the captured gas.

\begin{tabular}{|l|l|l|l|l|l|}
\hline & $\mathrm{CO}_{2}$ & $\mathrm{CO}$ & $\mathrm{N}_{2}$ & $\mathrm{C}_{2} \mathrm{H}_{4}$ & $\mathrm{C}_{3} \mathrm{H}_{6}$ \\
\hline Sim. 1 & 19.9 & 3.32 & 0.01 & 33.9 & 42.0 \\
\hline Sim. 2 & 22.0 & 3.92 & 0.01 & 34.2 & 41.2 \\
\hline
\end{tabular}

Figure 7 shows the comparison of the composition of the escaped gas. There are only small deviations between the experiments and the simulations. The escaped gas contains about 60 mole $\%$ nitrogen, but it also contains about $20 \%$ ethylene and $12 \%$ propylene in addition to the $\mathrm{CO}$ and $\mathrm{CO}_{2}$. This means that there is a large potential to recover more of the ethylene and propylene.

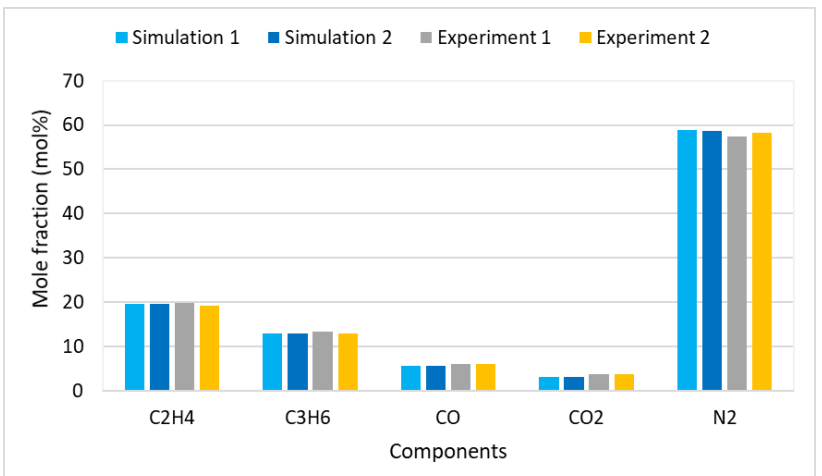

Figure 7. Comparison of simulated and experimental composition of escaped gas.

The simulated loss of each component through the escaped gas are presented in Table 7. The loss is defined 
as the mole $\%$ of the components in the feed leaving the absorber in the outlet gas. As can be seen from the table, more than half of the ethylene and propylene are lost in the outlet gas stream from the absorber.

Table 7. Simulated loss (in mole $\%$ of the feed) of the components through the escaped gas.

\begin{tabular}{|l|l|l|l|l|l|}
\hline & $\mathrm{CO}_{2}$ & $\mathrm{CO}$ & $\mathrm{N}_{2}$ & $\mathrm{C}_{2} \mathrm{H}_{4}$ & $\mathrm{C}_{3} \mathrm{H}_{6}$ \\
\hline Sim. 1 & 50.7 & 60.8 & 63.4 & 52.8 & 52.2 \\
\hline Sim. 2 & 50.6 & 60.7 & 63.2 & 52.9 & 52.3 \\
\hline
\end{tabular}

\subsubsection{Improvement of the simulation model}

In order to absorb all the ethyelene and propylene using the silver nitrate solution in the absorber, it is necessary to change parameters that affect the escaped gas quantity and quality. It is important here to look at the number of trays and the tray efficiency in the absorber. The number of trays are therefore increased from 1 to 5 , and the tray efficiency are increased from 0.5 to 0.7 . The actual tray efficiency depends on the flow rate of the feed gas and the absorbent. By increasing both these parameters in the absorber, almost all ethylene and propylene are solved in the silver nitrate solution. Packed absorbers are most efficient and have been used both for the validation and the improvement of the model.

The separation in the first distillation tower (Tower102), depends very much on the pressure. By specifying the pressure in the first distillation tower to $750 \mathrm{kPa}$, a significant amount of $\mathrm{N}_{2}$ and a small amount of $\mathrm{CO}$ is leaving in the vent gas, and the bottom product of the tower consists mainly of the silver nitrate solution, ethyelene and propylene in addition to some $\mathrm{CO}$ and $\mathrm{CO}_{2}$. The second distillation tower (Tower-103) can be operated at the same pressure $(61.3 \mathrm{kPa})$ as in the base case. The number of trays is kept at 3 in the first distillation tower and are increased from 1 to 2 in the second tower. The tray efficiency in both the distillation towers is 0.6 , and the reflux ratio is set to 0.3 . The simulation of the improved model was run with a mass flow rate of $234 \mathrm{~kg} / \mathrm{h}$ for the lean silver nitrate solution. The improved model gave a mass flow rate of $2.54 \mathrm{~kg} / \mathrm{h}$ for the outlet gas from the absorber, $2.2 \mathrm{~kg} / \mathrm{h}$ for the vent gas from the second distillation tower and $5.27 \mathrm{~kg} / \mathrm{h}$ for the captured gas. This is a significant improvement compared to the experimental results and the results from the base case simulations.

Figure 8 shows the gas composition in the captured gas. About $2 \mathrm{~kg}$ of ethylene and $2 \mathrm{~kg} / \mathrm{h}$ of propylene are recovered, which means a recovery of nearly $100 \%$. However, at the same time, the recovery of $\mathrm{CO}, \mathrm{CO}_{2}$ and nitrogen has also increased, which is not beneficial. A further improvement of the process is therefore needed as $\mathrm{CO}$ and $\mathrm{CO}_{2}$ are considered as poisons for the polymerization process, and it is crucial to minimize the content of those components in the purified gas. One solution is to change the temperature and pressure both in the absorber and the distillation towers. Increasing the temperature in the absorber, may reduce the absorption of $\mathrm{CO}$ and $\mathrm{CO}_{2}$, but it will also reduce the recovery of ethylene and propylene. Reducing the pressure in the distillation towers will release more of captured $\mathrm{CO}$, $\mathrm{CO}_{2}$ and $\mathrm{N}_{2}$ to the vent gas. The content of $\mathrm{CO}$ and $\mathrm{CO}_{2}$ has to be reduced to very low values, and a recovery of ethyelene and propylene in the range of $50-70 \%$ may therefore be acceptable.

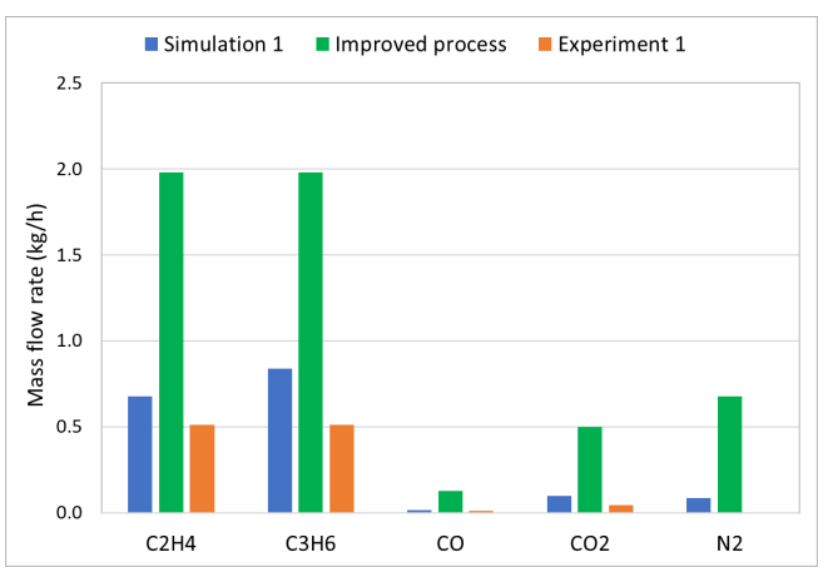

Figure 8. Comparison of the composition in the captured gas.

\section{Conclusion}

In order to extract ethylene and propylene from the plastic waste pyrolysis process, absorption process using silver nitrate solution as absorbent was selected as a promising technic. A lab scale set-up was built and experimental tests were performed to study the suitability of silver nitrate solution for extracting the hydrocarbons from the pollutants.

Aspen HYSYSV10 with the property package Electrolyte NRTL was used to model and simulate the absorption process. The model was validated against experimental data. The results from the simulations agreed well with the experimental data in terms of the mole fractions and the flow rates of captured gas. The validated model was further used to improve the separation process and increase the recovery of ethylene and propylene. The results from the improved process show that the amount of ethylene and propylene in the product gas increased significantly. In the experimental study, only $25 \%$ of ethylene and propylene in the feed was captured, whereas the simulation of the improved process increased the recovery of the monomers to $99 \%$. The product gas contains a relatively high amount of $\mathrm{CO}$ and $\mathrm{CO}_{2}$. The catalytic polymerization process will be poisoned or deactivated if $\mathrm{CO}$ and $\mathrm{CO}_{2}$ are present in the monomer feed gas, and it is crucial to reduce the concentration of these components below acceptable levels. The process simulation model has to be improved to obtain the low limits for $\mathrm{CO}_{2}$ and $\mathrm{CO}$. 


\section{Acknowledgements}

Norner Research AS is gratefully acknowledged for supervision and facilitation of the experimental work. The work was carried out in the project FuturePack Future Plastics Packaging in the Circular Economy, Grant no 267648, The Research Council of Norway.

\section{References}

K. P. Ananthapadmanabhan and E. D. Goddard. Process for the recovery of metal values, United States, 1988.

Available: http://www.freepatentsonline.com/4765834.html

Aspen. HYSYS, Software, and V8.6, Aspen HYSYS help, 2014.

C. C. Chen and Y. Song. Generalized electrolyte-NRTL model for mixed-solvent electrolyte systems, AIChE Journal, 50(8): 1928-1941, 2004.

A. Demirbas. Pyrolysis of municipal plastic wastes for recovery of gasoline-range hydrocarbons, Journal of Analytical and Applied Pyrolysis, 72(1): 97-102, 2004.

P. J. Donaj, W. Kaminsky, F. Buzeto, and W. Yang. Pyrolysis of polyolefins for increasing the yield of monomers' recovery, Waste management, 32(5): 840-846, 2012.

EPRO. Best Recycled Plastic Product Award, 2020, http:// www.epro-plasticsrecycling.org/

N. Ghasem, M. Al-Marzouqi, and N. Sheta. Effect of Pressure on the Separation of Ethylene from Ethylene/ Ethane Gas Mixture Using Hollow Fiber Membrane, Am. J. Polym. Sci, 7: 30-37, 2017.

G. Gourmelon. Global plastic production rises, recycling lags, Worldwatch Institute analysis explores trends in global plastic consumption and recycling, 2015.

D. K. Kannan. Process design of lab scale purification tool, Master thesis, University of South-Eastern Norway, 2019.

G. E. Keller, A. E. Marcinkowsky, S. K. Verma, and K. D. Williamson. Olefin recovery and purification via silver complexation, Separation and Purification Technology, 1, 1992.

N. Li. Separation and Purification Technology. CRC Press, 2013

H. Mortaheb, M. Mafi, A. Zolfaghari, B. Mokhtarani, N. Khodapanah, and F. Ghaemmaghami. Absorption of ethylene from ethylene-ethane gaseous mixture by AgNO3 solution in a semi-continuous process, The Canadian Journal of Chemical Engineering, 87(6): 957964, 2009.

A. K. Panda, R. K. Singh, and D. K. Mishra. Thermolysis of waste plastics to liquid fuel: A suitable method for plastic waste management and manufacture of value added products-A world prospective, Renewable and Sustainable Energy Reviews, 14(1): 233-248, 2010.

PlasticsEurope. Plastics - the Facts 2018,

https://www.plasticseurope.org/application/files/6315/4510/9 658/Plastics the facts 2018_AF_web.pdf

D. J. Safarik and R. B. Eldridge. Olefin/Paraffin Separations by Reactive Absorption: A Review, Industrial \& Engineering Chemistry Research, 37(7): 2571-2581, 1998.

Y. Xue, A. Kelkar, and X. Bai. Catalytic co-pyrolysis of biomass and polyethylene in a tandem micropyrolyzer, Fuel, 166: 227-236, 2016. 